\title{
RECRUITMENT AND DECISION-MAKING: THE EFFECTS OF EARLY RECRUIT- MENT PRACTICES ON THE DECISION TO APPLY TO AN ORGANIZATION
}

\author{
CHRISTOPHER J. COLLINS \\ Robert H. Smith School of Business \\ University of Maryland \\ College Park, MD 29742-1815 \\ (301) 405-2233 \\ ccollins@rhsmith.umd.edu \\ CYNTHIA KAY STEVENS \\ Robert H. Smith School of Business \\ University of Maryland
}

\begin{abstract}
This study explored the relationship between early recruitment practices (company visibility, social networking, campus presence and traditional practices) and decision making during the initial phase of the recruitment process. Results indicated that the relationship between early recruitment practices and decisions to apply were mediated by attraction and perceptions of organizational attributes.
\end{abstract}

\section{INTRODUCTION}

Many firms have adopted new and innovative recruitment practices to attract interest and attention from graduates, yet despite the substantial investments firms are making in such practices, most studies suggest weak or inconsistent relationships between early recruitment efforts and graduates' decisions (Barber, 1998). The purpose of this paper was to examine whether methodological enhancements - inclusion of multiple early practices, use of a contiguous outcome measure (i.e., the decision to apply), specification of mediating variables, and adoption of a within-subjects designwould enable us to detect a relationship between early recruitment practices and applicants' decisions. Moreover, we tested these ideas using an applicant sample of great interest to employers: graduating students from three top U.S. engineering programs. The paper first describes the range and possible effects of early recruitment practices on various proximal outcomes of interest. We then consider mediators of the recruitment practice-applicant decision relationship.

\section{BACKGROUND AND HYPOTHESES}

\section{Initial Phase of Recruitment and Early Recruitment Practices}

Barber (1998) proposed that recruiters may find stronger relationships if they focus on the distinct phases or cycles of recruiting: generating applicants, maintaining applicants' interest, and influencing job choices. She argued convincingly that the goal of recruitment practices at each phase should be to influence the decisions applicants make within that phase. In the initial phase of applicant generation, Barber suggested that organizations seek to attract the interest of potential applicants by providing information that will entice them to apply for existing openings. She noted that, al- 
though this phase is often overlooked, it is critically important to success at later phases because potential applicants who fail to apply implicitly reject any offers that might otherwise have been forthcoming.

Among the potential recruiting practices used by organizations during this initial phase, we identified four broad categories discussed in the academic or popular press. These included practices that: (a) seek to build an organization's image or visibility, (b) improve an organization's campus presence, (c) rely on social networks to disseminate information, and (d) provide information about openings through traditional means.

\section{Matching Recruitment Practices with Appropriate Outcome Variables}

Another possible explanation for weak findings in prior research is that researchers have focused on the wrong outcome variables. The theory of reasoned action (Ajzen \& Fishbein, 1980), when applied to the recruitment context, would suggest that recruitment practices will have stronger effects on actions that are proximal to exposure to those practices. Both Barber (1998) and Rynes (1991) have argued that the critical outcomes for early recruitment practices are increased attraction and the decision to apply for available openings.

Some evidence suggests that recruitment practices which convey positive images of organizations may influence potential applicants' attitudes/ reactions towards an organization. For example, Gatewood et al. (1993) found that recruitment practices may improve students' early impressions of organizations and their willingness to apply for openings. Similarly, Barber and Roehling (1993) found that the presentation of a greater amount of and more positive information using traditional practices increased potential applicants' attraction and willingness to apply for openings.

Hypothesis 1: All four early recruitment practices will be positively related to applicants' attraction to organizations and their intentions to apply for openings.

Although the majority of recruitment research to date has focused on applicant reactions, it is critical to examine the links between recruitment practices and actual decisions to fully understand how recruitment practices affect decision-making (Barber, 1998). In a lab study, Barber and Roehling (1993) found that students decided not to apply to all of the available organizations with openings and that the message conveyed by the job postings influenced their application decisions. Therefore, we predicted that:

Hypothesis 2: All four early recruitment practices will be positively related to potential applicants' decisions to apply for openings.

\section{Mediators of the Recruitment-Decision Relationship}

Although recruitment practices may affect attraction, intentions, and decisions to apply, some evidence suggests that recruitment effects on behavior are mediated by attitudinal changes (Harris \& Fink, 1987; Stevens, 1997). Specifically, recruitment-practice effects on attraction should mediate their impact on both intentions and decisions to apply for openings: 
Hypothesis 3: The effects of the four early recruitment practices on potential applicants' intentions to apply for openings and actual application decisions will be mediated by attraction.

A second potential mediator of the recruitment practice-outcome relationship is potential applicants' perceptions of job attributes. Early recruitment practices may influence potential applicants' decisions by helping them to form favorable impressions of job attributes. Rynes, Bretz, and Gerhart (1991) suggested that recruitment effects may be strongest when applicants possess little information about organizations; as such, the impact of early recruitment practices may be particularly strong. This influence may operate directly, through the provision of specific information about organizations and their openings (e.g., social networks or traditional recruitment practices). Alternatively, it may operate indirectly through signaling or "halo" effects in which generalized positive impressions lead potential applicants to infer that unknown attributes will be positive. Thus, we predicted:

Hypothesis 4: The effects of the four early recruitment practices on potential applicants' intentions and actual decisions to apply will be mediated by their perceptions of job attributes.

Previous research has shown that applicants' intentions to accept job offers are strongly and positively related to their actual decisions when job offers have been extended (Stevens, 1997; Turban, Campion, \& Eyring, 1995). Given that behavioral intentions typically precede actual decisions, we expected that intentions to apply for openings would be strongly and positively associated with actual applications.

Hypothesis 5: Potential applicants' intentions to apply to specific organizations will be positively related to their actual application decisions.

\section{METHOD}

\section{Sample and Procedures}

Respondents included 133 students graduating with Bachelor's or Master's degrees in engineering from three universities. Nearly $70 \%$ of the respondents were men, but the sample was ethnically diverse $(65 \%$ white, $24 \%$ Asian, $5 \%$ African-American, and $6 \%$ other) with an average GPA of $3.24,2.56$ years of full-time work experience and 1.40 years of engineering work experience.

The study used a within-subjects design, in which respondents were asked to list up to 10 organizations in which they had some interest. For each organization listed, respondents rated the recruitment practices to which they had been exposed and their perceptions of job attributes, attraction, and intentions. A follow-up survey sent two months later asked whether respondents had applied for openings with each of the organizations listed on the first survey.

\section{RESULTS}

Fixed-effects regressions were used to test the hypotheses because of the within-subjects design 
that was used. Hypothesis 1 predicted that there would be positive relationships between each of the four early recruitment practices and both attraction and application intentions. Each of the early recruitment practices was significantly related to attraction: visibility $t=6.00, p<.001$; campus presence $\mathrm{t}=-2.40, \mathrm{p}<.01$; social networking $\mathrm{t}=10.19, \mathrm{p}<.001$; and traditional practices $\mathrm{t}=4.95$, $\mathrm{p}<.001$. Three of the early recruitment practices were significantly related to intentions: visibility $\mathrm{t}=3.82, \mathrm{p}<.001$; campus presence $\mathrm{t}=-3.53, \mathrm{p}<.001$; and social networking $\mathrm{t}=10.36, \mathrm{p}<.001$. Thus, the data generally supported the hypothesized relationships between early recruitment practices and both dependent measures.

Hypothesis 2 predicted that there would be positive relationships between all four early recruitment practices and respondents' actual application decisions. Because the decision to apply is a dichotomous variable, we tested this hypothesis with probit analysis. Three of the early recruitment practices significantly predicted students' application decisions (campus presence Chi-Square $=5.23$, $\mathrm{p}<.05$; social networking Chi-Square $=24.68, \mathrm{p}<.001$; traditional practices Chi-Square $=4.66, \mathrm{p}$ $<.05)$. Thus, the data generally supported the hypothesized relationships between early recruitment practices and decisions.

Hypothesis 3 predicted that attraction would mediate the relationship between early recruitment practices and both intentions and actual decisions. The recruitment-attraction-intentions relationship was tested through a hierarchical fixed effects regression. Attraction was significantly related to intentions $(\mathrm{t}=24.54, \mathrm{p}<.001)$, but two of the three early recruitment practices remained significant after controlling for attraction (campus presence $\mathrm{t}=-2.59, \mathrm{p}<.05$, and social networking $\mathrm{t}=$ $4.43, \mathrm{p}<.001)$. The previously significant effect for visibility on intentions was eliminated after controlling for attraction. Using a procedure discussed by Clogg, Petkova, \& Shihadeh (1992), we found that the relationships between the recruitment variables and intentions were significantly reduced. Thus, the findings supported the hypothesis that attraction mediates — at least partially — the relationship between early recruitment practices and intentions.

The recruitment-attraction-decisions relationship was tested through a hierarchical probit analysis. Attraction was significantly related to decisions (Chi-Square $=64.26, \mathrm{p}<.001$ ), and none of the three early recruitment practices that were significant in the first model remained significant when attraction was added. Thus, the findings supported the hypothesis that attraction mediates the relationship between early recruitment practices and decisions to apply to specific companies.

Hypothesis 4 predicted that job attributes would mediate the relationship between early recruitment practices and both intentions and actual decisions. All four early recruitment practices were significantly related to job attributes: visibility $\mathrm{t}=5.99, \mathrm{p}<.001$; campus presence $\mathrm{t}=-2.95, \mathrm{p}<.01$; social networking $\mathrm{t}=10.81, \mathrm{p}<.001$, traditional practices $\mathrm{t}=3.69, \mathrm{p}<.001$ ). After adding job attributes to the regression model predicting intentions, we found that the relationships between two recruitment practices and intentions remained significant after controlling for job attributes (campus presence $\mathrm{t}=-2.36, \mathrm{p}<.05$, social networking $\mathrm{t}=5.17, \mathrm{p}<.001$ ); however, these relationships were significantly reduced when job attributes was added and the previously significant effect for visibility was eliminated. Thus, the data suggested that job attributes partially mediated the recruitment practices-intentions relationship.

Hypothesis 5 predicted that application intentions would be positively related to the actual decision 
to apply to organizations. Intentions were significantly related to application decisions (Chi-Square $=11.90, \mathrm{p}<.001$ ), even after controlling for all other variables related to application decisions. Thus the data strongly supported Hypothesis 5.

\section{DISCUSSION}

The study findings confirmed several hypotheses about how early recruitment practices influence the decision to apply to an organization. Specifically, all four early recruitment practices - visibility, campus presence, social networks, and traditional means - were related to potential applicants' attraction and three practices were also related to intentions and decisions. Moreover, perceived job attributes and organizational attraction partially mediated the relationship between these practices and intentions, whereas intentions fully mediated the impact of practices on decisions.

Our findings suggested that the relationships between early recruitment practices and application intentions was not simple or direct. The relationship between early recruitment and intentions was partially mediated by attraction (Hypothesis 3) and perceptions of job attributes (Hypothesis 4). Potential applicants were more likely to intend to apply to organizations when they perceived early recruitment practices in a positive light, because these practices signaled a the presence of desirable job attributes and increased organizational attraction.

A similar set of results were found for the relationship between recruitment practices and decisions to apply. We found that the relationship between early recruitment and decisions was fully mediated by attraction (Hypothesis 3 ) and partially mediated by perceived job attributes (Hypothesis 4). Additionally, we found that the relationships between early recruitment practices and attraction were partially mediated by perceived job attributes. Thus, it appears that when applicants perceived an organization's early recruitment practices in a positive light, they were more likely to apply to that organization because recruitment made the organization appear more attractive by signaling the presence of desired job attributes. In addition, our findings lend further support to a growing body of research that established a strong link in the recruitment literature between intentions and actions (Hypothesis 5). Our findings suggest that recruitment indirectly affects intentions which, in turn, directly affect actual application decisions.

The use of a within-subjects design and fixed-effects regression allowed us remove individual differences and estimate the average effects of early recruitment practices across all respondents. These results suggested that firms using a wider variety of early recruitment practices have a greater chance to attract applicants than those using a narrow range of practices. However, for organizations with limited resources or recruiting budgets, our findings suggest that some early recruitment practices are particularly effective. In particular, social networking had the largest effect on both attraction and application intentions.

There are several limitations to the study. The most serious concern, given the cross-sectional nature of the data, is that it was not possible to determine the direction of causality for the relationships between recruitment practices, attitudes/reactions, and intentions. Because most of the data were collected at the same time, we cannot rule out the possibility of reverse causality for these relationships that were examined. A related problem is that, by asking the respondents to rate multiple companies, we were limited in the number of predictor variables that could be feasibly includ- 
ed. Therefore, there may be several unmeasured variables that could provide alternative explanations for the findings.

Overall, the study results depict a complex picture of how recruitment practices influence potential applicants' decisions. The findings provide further support for our suggestion that future researchers should examine a broader range of practices, consider potential mediators, use proximal outcome measures, and employ within-subjects designs. From a practical standpoint, the findings suggest that early recruitment practices can be used successfully to influence potential applicants' decisions. Considering that there is a large shortage of skilled engineering graduates, such early advantages may translate into strategic advantages in the capacity to generate and maintain new business.

\section{REFERENCES}

Ajzen, I., \& Fishbein, M. 1980. Understanding attitudes and predicting social behavior. Englewood Cliffs, NJ: Prentice Hall.

Barber, A. E. 1998. Recruiting employees: Individual and organizational perspectives.

Thousand Oaks, CA: Sage Publications.

Barber, A.E., \& Roehling, M. V. 1993. Job postings and the decision to interview: A verbal protocol analysis. Journal of Applied Psychology, 78, 845-856.

Clogg, C. C., Petkova, E., \& Shihadeh, E. S. 1992. Statistical methods for analyzing collapsibility in regression models. Journal of Educational Statistics, $\underline{17}$, 447-488.

Gatewood, R. D., Gowan, M. A., Lautenschlager, G. J. 1993. Corporate image, recruitment image, and initial job choice. Academy of Management Journal, $\underline{36}, 414-427$.

Harris, M. M, \& Fink, L. S. 1987. A field study of applicant reactions to employment opportunities: Does the recruiter make a difference. Personnel Psychology, 40, 765-786.

Munk, N. 1998. The new organization man. Fortune, 137(5), 62-74.

Rynes, S. L. 1991. Recruitment, job choice, and post-hire consequences. In Dunnette, M.D., \& Hough, L. M. (Eds.), Handbook of industrial and organizational psychology (2nd ed.), Vol. 2: 399444. Palo Alto, CA: Consulting Psychologists Press.

Rynes, S. L., Bretz, R. D., \& Gerhart, B. 1991. The importance of recruitment in job choice: A different way of looking. Personnel Psychology, $\underline{44}, 487-521$.

Stevens, C. K. 1997. Effects of preinterview beliefs on applicants' reactions to campus interviews.

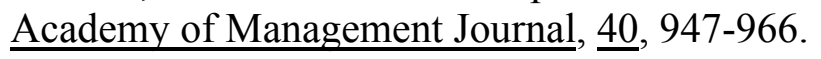

